\title{
MECP2 duplication syndrome in a Chinese family
}

\author{
Qingping Zhang, Ying Zhao, Yanling Yang and Xinhua Bao*
}

\begin{abstract}
Background: Methyl-CpG-binding protein 2 (MeCP2) is a key transcriptional regulator of gene expression in the maintenance and development of the central nervous system. Loss- or gain-function of this gene may contribute to neurodevelopmental disorders. The aim of this study is to delineate the clinical characteristics of MECP2 duplication syndrome and the hereditary mechanism in a Chinese family.

Case presentation: We identified a Chinese family with three persons carry MECP2 gene duplication: a boy, his mother and his grandmother. The duplication segment which was detected by multiplex ligation-dependent probe amplification (MLPA) included gene MECP2, interleukin-1 receptor-associated kinase 1 (IRAK1), filamin A (FLNA), and L1 cell adhesion molecule (LICAM). Furthermore, array comparative genomic hybridization (aCGH) was performed on the mother, showed that MECP2 containing duplication was $510 \mathrm{~Kb}(153,113,885-153,624,154)$, including 16 other genes except MECP2. The boy showed most symptoms of MECP2 duplication syndrome. His mother and maternal grandmother were asymptomatic. Both female carriers had a skewed X chromosome inactivation $(X C l)$, which were 80:20 and 74:26 respectively.

Conclusion: To our knowledge, this is the second reported Chinese Han family with MECP2-containing duplications. And this patient had recurrent respiratory infections which was different from the first two Chinese-brother cases. $M E C P 2$ is the core gene responsible for MECP2 duplication syndrome. $\mathrm{XCl}$ may play an important role in modulating the clinical manifestation.
\end{abstract}

Keywords: MECP2 duplication syndrome, Chinese family, MLPA, aCGH, Skewed X chromosome inactivation

\section{Background}

Methyl-CpG-binding protein 2 (MECP2) located at Xq28 acts as a transcriptional repressor or activator regulating the genes associated with nerve system development [1]. Loss-of-function mutations of $M E C P 2$ gene are the cause of most cases of Rett syndrome (RTT, OMIM: 312750). RTT is a neurodevelopmental disorder which affects $1 /$ 10,000 girls. Recent studies found that duplications involving $M E C P 2$ gene and increased $M E C P 2$ protein dosage can cause a severe syndromic developmental delay (DD), mental retardation (MR), and recurrent infections. It was found in $1 \%$ of patients with idiopathic X-linked MR (XLMR) and in $2 \%$ of male patients with severe encephalopathy [2]. It was named $M E C P 2$ duplication syndrome $(M E C P 2 D S)$, a newly described genetic condition, and gain-of-function mutations of $M E C P 2$.

\footnotetext{
* Correspondence: zwhang@pku.edu.cn

Department of Pediatrics, Peking University First Hospital, No.1, Xi An Men Street, Xicheng District, Beijing 100034, China
}

The cardinal features of the syndrome include early onset hypotonia, moderate to profound mental retardation, delayed psychomotor development, speech delay or absent to very limited speech, seizures, progressive spasticity in male patients. Dysmorphism is common and some features changed with age. Midface hypoplasia, depressed nasal bridge and a hypotonic face such as open mouth with tented upper lip, excessive drooling present in most patients at young age. When time goes by, some additional facial features may appear: a narrow nose, prominent chin, deep-set eyes, large ears, and widely spaced teeth [3]. Genital anomalies, including cryptorchidism and small penis, were reported in some cases. Patients with congenital central hypoventilation syndrome (CCHS), hyperkinesis were also reported $[4,5]$. Half of these patients have a short lifespan less than 25-year-old [6]. The animal model with over expression both the mouse and human MECP2 gene showed similar neurological symptoms including epilepsy, spasticity, hypoactivity and short lifespan. The 
severe phenotype is correlated with the higher Mecp2 protein level $[7,8]$.

Here we report a Chinese boy with $M E C P 2$ duplication syndrome, who inherited the duplicated gene from his unaffected mother, while his mother inherited the duplicated gene from his unaffected grandmother. The genetic characters and the clinical features are presented.

\section{Case presentation}

\section{Case report}

The patient is a 2-year-4-month-old boy, who is the first child of his nonconsanguineous Chinese parents, a 26year-old mother and a 27-year-old father, both of them are healthy. Following an uneventful pregnancy, he was born at 38 weeks of gestation with a birth weight of $3.15 \mathrm{~kg}$. Feeding difficulties and poor suck had been noticed since birth. Hypotonia was apparent at age of 4 months. He showed severe developmental delay. $\mathrm{He}$ could not raise his head until 4 months old, sit unsupported till 11 months. At 2-year-4-month-old, he could not walk and speak any meaningful words. Eye contact and social smiling were enabling. He had recurrent respiratory tract infections, and hospitalized for severe pneumonia for several times. At 12 months old, his head circumference was $47 \mathrm{~cm}$, weight was $11 \mathrm{~kg}$. The boy had mild dysmorphism with flat nasal bridge, anteverted nares, small mouth, high-arched palate, low-set ears and cryptorchidism of the right side. Hand stereotypes including hand wringing and hand shaking presented at 8 months. He had no chronic constipation, no seizures. Magnetic resonance imaging (MRI) at age 1 year was unremarkable. Karyotype analysis was normal. Serum amino acid and urine organic acid screen were unremarkable.

Family history: The boy's mother had two younger brothers. Both of them had severe developmental delay. The elder one could not walk or speak before he died at age of 5 . The best motor function was sitting unaided. His brain computed tomography (CT) scan showed generalized cerebral atrophy. The younger one had a history of recurrent infections, died of a sever pneumonia at the age of $1 \mathrm{y}$. He could not sit or walk alone during his life, speak no meaningful words yet. Both the mother and the grandmother were asymptomatic, they did not have any symptoms of depression, anxiety and compulsions. Figure 1 showed the pedigrees of the family, the proband was showed by an arrow.

\section{MLPA tests}

Genomic DNAs from the peripheral blood leukocytes of the patient, his parents and the maternal grandmother were extracted using standard methods. MLPA (SALSA MLPA kit P015 MECP2, MRC-Holland, Amsterdam, Holland) was performed to detect large deletions or duplications of $M E C P 2$ gene as previously described [9].

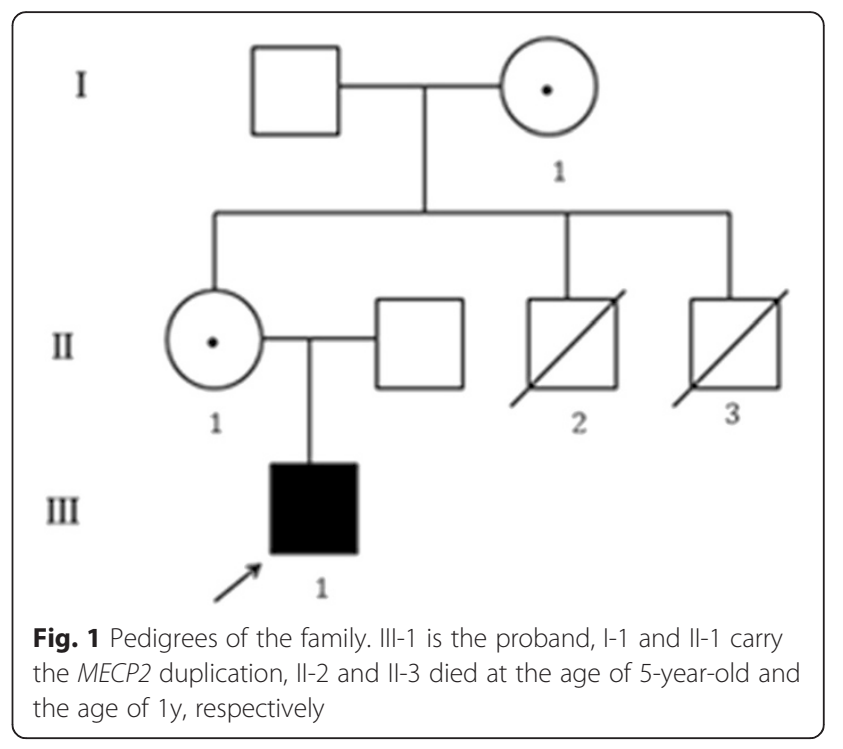

MLPA products were separated and analyzed using the ABI Prism 3100 Genetic Analyzer and Genescan software according to manufacturer's recommendations.

\section{aCGH analysis}

In order to determine the precise size of the duplication, aCGH was performed on the mother' DNA, using Affymetrix GeneChip System 3000Dx v.2 (by Tianjin kingmed center for clinical laboratory, Shanghai, China).

\section{Fluorescence in situ hybridization (FISH)}

FISH test was performed to interrogate the MECP2 copy number and to identify the location of the duplicated MECP2 gene in chromosome (done by Beijing Ahngook Pharm. Co., Ltd, Beijing, China).

\section{$\mathrm{X}$ chromosome inactivation patterns (XCl)}

The patterns of $\mathrm{XCI}$ of female carriers were analyzed according to the procedure described by Allen et al. [10]. Inactivation was considered to be non- random if the ratio was $>70: 30$.

\section{Results}

DNA fragment duplication was found in the patient, his mother and maternal grandmother by MLPA test. The fragment range from X-152,783,270 to X-153,239,085, including $\mathrm{L} 1$ cell adhesion molecule gene (L1CAM; OMIM \#308840), interleukin-1 receptor-associated kinase 1 (IRAK1; OMIM \#300283), MECP2, filamin A (FLNA; OMIM \#300017) and other genes, that probes were not designed in the kit P015 (Fig. 2).

aCGH was performed on the proband's mother to test the precise size of the duplicated fragment. The result showed that the duplication fragment was 510, $270 \mathrm{bps}$ $(153,113,885-153,624,154)$ containing 17 genes (Table 1), 

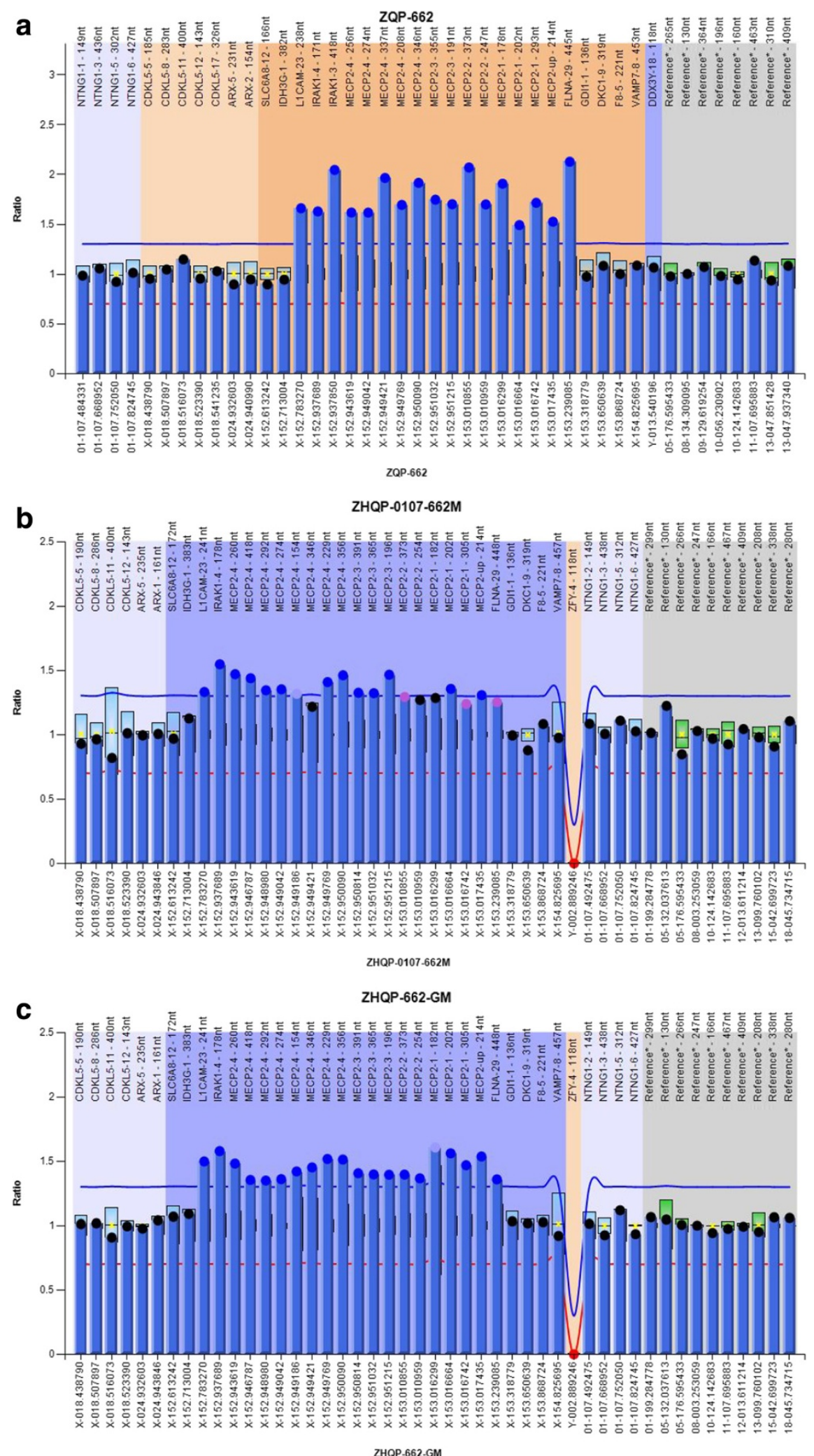

Fig. 2 Genes duplication in the proband (a), his mother $(\mathbf{b})$ and his grandmother $(\mathbf{c})$, tested by MLPA 
Table 1 Duplicated genes and their positions

\begin{tabular}{ll}
\hline Gene & Position \\
\hline L1 cell adhesion molecule (L1CAM) & $X: 153,126,969-153,141,500$ \\
Arginine vasopressin receptor 2 (AVPR2) & $X: 153,170,428-153,172,620$ \\
Rho GTPase activating protein 4 (ARHGAP4) & $X: 153,172,830-153,191,714$ \\
N (alpha)-acetyltransferase 10 (NAA10) & $X: 153,195,280-153,200,607$ \\
Renin binding protein (RENBP) & $X: 153,200,722-153,210,232$ \\
Host cell factor C1 (HCFC1) & $X: 153,213,008-153,236,819$ \\
Transmembrane protein 187 (TMEM187) & $X: 153,237,991-153,248,646$ \\
MicroRNA 3202-1 (MIR3202-19) & $X: 153,246,548-153,246,628$ \\
MicroRNA 3202-2 (MIR3202-2 ${ }^{a}$ ) & $X: 153,246,549-153,246,627$ \\
Interleukin-1 receptor-associated kinase 1 (IRAK1) & $X: 153,275,957-153,285,342$ \\
MicroRNA 718 (MIR718) & $X: 153,285,371-153,285,440$ \\
Methyl CpG binding protein 2 (MECP2) & $X: 153,287,264-153,363,188$ \\
Opsin 1 (cone pigments), long-wave-sensitive (OPN1LW) & $X: 153,409,725-153,424,507$ \\
Opsin 1 (cone pigments), medium-wave-sensitive (OPN1MW) & $X: 153,485,203-153,499,470$ \\
Testis expressed 28 (TEX28) & $X: 153,498,929-153,523,563$ \\
Transketolase-like 1 (TKTL1) & $X: 153,524,027-153,558,713$ \\
Filamin A, alpha (FLNA) & $X: 153,576,900-153,603,006$ \\
Emerin (EMD) & $X: 153,607,597-153,609,883$
\end{tabular}

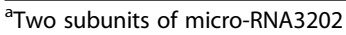

including two subunits of Micro-RNA (MIR3202), starting from $L 1 C A M$ and ending with emerin (EMD; OMIM \#300384). There was no gene coming across the breakpoints.

FISH test was performed on the mother. The red fluorescence signals representing $M E C P 2$ gene were seen on each $\mathrm{X}$ chromosome, and only one fluorescence signal could be seen on each X chromosome (Fig. 3). That means the duplicated $M E C P 2$ gene was located at $\mathrm{X}$ chromosome next to the original MECP2 gene.

The XCI pattern analysis showed the XCI ratio of the patient's mother and maternal grandmother was 80:20 and 74:26, respectively. The $\mathrm{X}$ chromosome carrying the duplication was $80 \%$ inactive in the mother and $74 \%$ inactive in the grandmother. The proband inherited the $\mathrm{X}$ chromosome carrying the duplication variant from his mother.

\section{Discussion}

With the development of new techniques, some genomic disorders such as Williams-Beuren syndrome (WBS, MIM 194050), Potocki-Lupski syndrome (PTLS, MIM 610883), Miller-Dieker syndrome (MDS, MIM 247200), were found to be caused by the alteration of gene dosage, or copy number variation (CNV) [11]. MECP2 gene acting as a transcriptional regulator of gene expression should express very accurate level in cells. Loss-of-function of $M E C P 2$ leads to Rett syndrome while gain-of-function causes $M E C P 2$ duplication syndrome. In additional, patient with Xq28 rearrangement containing $M E C P 2$ triplication was considered to be more severe than MECP2 duplication [12, 13]. Animal models also demonstrated this phenomenon.

MECP2 duplication is most common among the $\mathrm{Xq} 28$ rearrangement. The reported duplications differed in size and location (except the carrier mom and inherited

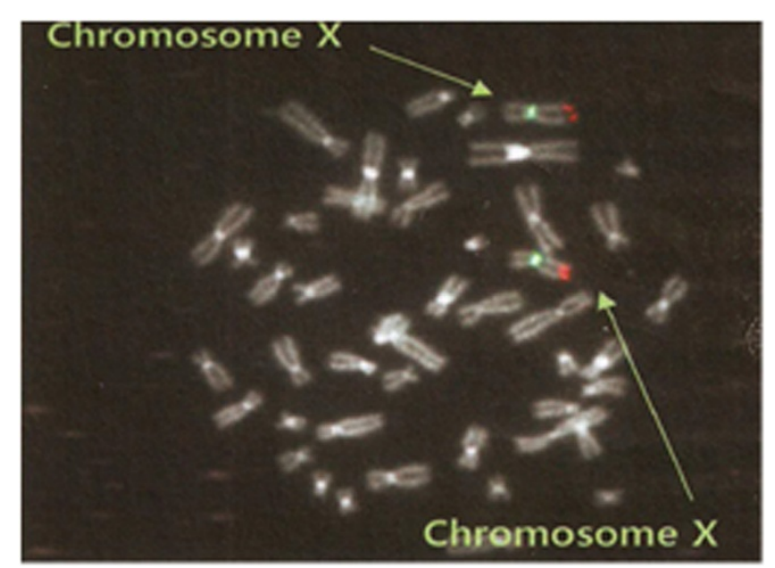

Fig. 3 Two-color fluorescence in situ hybridization analysis of the mother with MECP2 gene duplication. The duplicated MECP2 gene was located at $X$ chromosome, and only one fluorescence signal can be seen on each $X$ chromosome. Green signal is a control single-copy probe, hybridized to alpha satellite DNA at the chromosome $X$ centromere. Red signal on distal Xq is a probe for the MECP2 gene, which is present on each $X$ chromosome 
offspring), were defined as non-recurrent events. The flanking region around $M E C P 2$ gene is abundant of lowcopy repeat (LCR) sequences and high GC content, which generated the genomic instability such as double-strand breaks (DSBs) and a collapsed fork. The molecular mechanisms of MECP2 copy number variation were proposed by mainly two ways: one is Fork Stalling and Template Switching (FoSTeS), another is microhomology mediated break-induced replication (MMBIR) [14-17].

In the previous reports, the sizes of the duplications encompassing $M E C P 2$ locus vary between $79.7 \mathrm{kbs}$ and $15.5 \mathrm{Mbs}[18,19]$. The smallest duplication only contains MECP2 and IRAK1 genes. The duplication size in our patient was about $510 \mathrm{kbs}$, including 17 genes, starting from L1CAM and ending with EMD. L1CAM, IRAK1, MECP2 and FLNA were embraced in the duplication. These four genes play important roles in postnatal nervous system development. L1CAM and MECP2 were associated with Xlinked mental retardation (XLMD). IRAK1, encoding an interleukin receptor-associated kinase was involved in the toll-like receptor transduction pathway, was a critical signaling mediator of innate immunity. Gottipati et al. found that over expression of this gene might lead to the susceptibility to infections [20]. However, Yang and colleagues identified immune defects among the patients with MECP2 DS had no association with IRAK1 duplication by transgenic mice that overexpressed MECP2 without IRAK1 duplication [21]. This conclusion was supported by Sawalha [22]. Chronic intestinal pseudo-obstruction (CIPO), thrombcytopaenia, patent ductus arteriosus (PDA), malrotation were found in two families with the duplications involved only the FLNA gene [23]. One case suffered CCHS also had chronic constipation without duplication of FLNA [24]. Some other genes in the duplicated area of our patient may be associated with mental retardation and development delay. Huang et al. reported 2 male-dizygotic-twins with a 17.9-kbs deletion of Xq28 including Arginine vasopressin receptor-2 gene (AVPR2; OMIM 300538) and extending into intron 7 of the RHO GTPase-activating protein 4 gene (ARHGAP4; OMIM 300023). They were diagnosed with nephrogenic diabetes insipidus (NDI) as well as psychomotor developmental delay [25]. Host cell factor $\mathrm{C} 1$ gene (HCFC1; OMIM 300019) was reported to be associated with X-linked mental retardation (XLMR) [26]. The clinical manifestation of our patient was characterized by developmental delay, early hypotonia, recurrent infection, and mild dysmorphism, without CIPO, PDA and NDI. Combined our study and previous reports, most of the symptoms of $M E C P 2 D S$ should be attributed to gain of MeCP2 function.

Family study showed the mother and maternal grandmother also carried the MECP2 duplication. The patient inherited the mutation from them. FISH test on the mother showed the duplicated MECP2 gene was located at X chromosome. However, the mother and the maternal grandmother were asymptomatic. Further XCI study showed the XCI pattern was non-random in both of them. The ratio was $80: 20$ and 74:26 respectively. The $X$ chromosome carrying the duplication was prioritized inactive. This molecular phenomenon may explain their asymptomatic phenotype. In the previous reports, almost all the asymptomatic carriers were with a skewed $\mathrm{XCI}$ except one with XCI ratio 43:57 [27]. However, the XCI ratio in peripheral blood DNA may not represent the ratio in Brain. It could be inconsistent in different tissues. A mother of a $M E C P 2$ DS patient had mild learning difficulties with a complete skewed XCI in the blood DNA while the ratio was 74:26 in her hair roots. The authors speculated that the inactivation of $\mathrm{X}$ chromosome with MECP2 duplication in her brain was not completely leading to her mild clinical features [28]. This is the only literature about XCI test performed on the other tissue rather than blood in patients with $M E C P 2$ DS. In this family, two maternal uncles of the boy had severe developmental delay, severe mental retardation and recurrent infections. Both of them died at young age. They were highly suspected to be patients with MECP2 DS.

\section{Conclusions}

In this study, we demonstrate one more Chinese family with $M E C P 2$ duplication syndrome. The main clinical features include early onset hypotonia, mental retardation, recurrent respiratory tract infections, limited speech and dysmorphism. Female carrying the MECP2 duplication could be asymptomatic due to the skewed XCI. In order to make an accurate diagnosis and provide a right genetic counseling, genomic structure rearrangement, especially MECP2 duplication should be tested in the patients with the above symptoms as well as other family members.

\section{Consent}

Gene mutational analysis on the family members and the study of the XCI patterns in female carriers began after signing an informed consent by the parents. Ethical approval was obtained from the hospital research ethic board. Written informed consent was obtained from the legal guardian of the patient for publication of this Case report and any accompanying images. A copy of the written consent is available for review by the Editor of this journal.

\section{Competing interests}

The authors declare no conflict of interests.

\section{Authors' contributions}

XB obtained the funding and design the research. QZ, YZ, and YY collected clinical data and samples from the family members. QZ carried out the laboratory work, YZ helped preparing the laboratory work. QZ analyzed most of the data and draft the manuscript. XB, YZ and YY revised the manuscript. All authors read and approved the final manuscript. 


\section{Acknowledgements}

We thank the patient and his family for participating the study. This study was financially supported by Beijing Municipal Science \& Technology Commission No. Z121107001012049 (capital clinical characteristic application research), 985 Peking University and Clinical Hospital Cooperation Project.

Received: 26 April 2015 Accepted: 14 December 2015

Published online: 16 December 2015

\section{References}

1. Chahrour M, Jung SY, Shaw C, Zhou X, Wong ST, Qin J, et al. MeCP2, a key contributor to neurological disease, activates and represses transcription. Science. 2008;320(5880):1224-9.

2. Lugtenberg D, Kleefstra T, Oudakker AR, Nillesen WM, Yntema HG, Tzschach A, et al. Structural variation in Xq28: MECP2 duplications in $1 \%$ of patients with unexplained XLMR and in $2 \%$ of male patients with severe encephalopathy. Eur J Hum Genet. 2009;17(4):444-53.

3. Bartsch O, Gebauer K, Lechno S, van Esch H, Froyen G, Bonin M, et al. Four unrelated patients with Lubs $X$-linked mental retardation syndrome and mental retardation syndrome and different Xq28 duplications. Am J Med Genet A. 2010;152A(2):305-12.

4. Belligni EF, Palmer RW, Hennekam RC. MECP2 duplication in a patient with congenital central hypoventilation. Am J Med Genet A. 2010;152A(6):1591-3.

5. Budisteanu M, Papuc SM, Tutulan-Cunita A, Budisteanu B, Arghir A. Novel clinical finding in MECP2 duplication syndrome. Eur Child Adolesc Psychiatry. 2011;20(7):373-5.

6. Van Esch H. MECP2 duplication syndrome. Mol Syndromol. 2011;2(3-5):128-36.

7. Collins AL, Levenson JM, Vilaythong AP, Richman R, Armstrong DL, Noebels JL, et al. Mild overexpression of MeCP2 causes a progressive neurological disorder in mice. Hum Mol Genet. 2004;13(21):2679-89.

8. Luikenhuis S, Giacometti E, Beard CF, Jaenisch R. Expression of MeCP2 in postmitotic neurons rescues Rett syndrome in mice. Proc Natl Acad Sci U S A. 2004;101(16):6033-8.

9. Amir RE, Van den Veyver IB, Wan M, Tran CQ, Francke U, Zoghbi HY. Rett syndrome is caused by mutations in X-linked MECP2, encoding methylCpGbinding protein 2. Nat Genet. 1999;23(2):185-8.

10. Allen RC, Zoghbi HY, Moseley AB, Rosenblatt HM, Belmont JW. Methylation of Hpall and Hhal sites near the polymorphic CAG repeat in the human androgen-receptor gene correlates with $\mathrm{X}$ chromosome inactivation. Am J Hum Genet. 1992:51(6):1229-39.

11. Gu W, Lupski JR. CNV and nervous system disease - what's new? Cytogenet Genome Res. 2008;123(1-4):54-64.

12. del Gaudio D, Fang P, Scaglia F, Ward PA, Craigen WJ, Glaze DG, et al. Increased MECP2 gene copy number as the result of genomic duplication in neurodevelopmentally delayed males. Genet Med. 2006;8(12):784-92.

13. Tang SS, Fernandez D, Lazarou LP, Singh R, Fallon P. MECP2 triplication in 3 brothers - a rarely described cause of familial neurological regression in boys. Eur J Paediatr Neurol. 2012;16(2):209-12.

14. Lee JA, Carvalho CM, Lupski JR. A DNA replication mechanism for generating nonrecurrent rearrangements associated with genomic disorders. Cell. 2007; 131(7):1235-47.

15. Bauters M, Van Esch $H$, Friez MJ, Boespflug-Tanguy O, Zenker M, Vianna-Morgante AM, et al. Nonrecurrent MECP2 duplications mediated by genomic architecture-driven DNA breaks and break-induced replication repair. Genome Res. 2008;18(6):847-58.

16. Carvalho CM, Zhang F, Liu P, Patel A, Sahoo T, Bacino CA, et al. Complex rearrangements in patients with duplications of MECP2 can occur by fork stalling and template switching. Hum Mol Genet. 2009;18(12):2188-203.

17. Hastings PJ, Lupski JR, Rosenberg SM, Ira G. Mechanisms of change in gene copy number. Nat Rev Genet. 2009;10(8):551-64.

18. Sanmann JN, Bishay DL, Starr L, Bell CA, Pickering DL, Stevens JM, et al. Characterization of six novel patients with MECP2 duplications due to unbalanced rearrangements of the X chromosome. Am J Med Genet Part A. 2012;158A(6):1285-91.

19. Breman AM, Ramocki MB, Kang SH, Williams M, Freedenberg D, Patel A, et al. MECP2 duplications in six patients with complex sex chromosome rearrangements. Eur J Hum Genet. 2011;19(4):409-15.

20. Gottipati S, Rao NL, Fung-Leung WP. IRAK1: a critical signaling mediator of innate immunity. Cell Signal. 2008;20(2):269-76.
21. Yang T, Ramocki MB, Neul JL, Lu W, Roberts L, Knight J, et al. Overexpression of methyl-CpG binding protein 2 impairs $\mathrm{TH} 1$ responses. Sci Transl Med. 2012;4(163):163ra158.

22. Sawalha AH. Overexpression of methyl-CpG-binding protein 2 and autoimmunity: evidence from MECP2 duplication syndrome, lupus, MECP2 transgenic and Mecp2 deficient mice. Lupus. 2013;22(9):870-2.

23. Clayton-Smith J, Walters S, Hobson E, Burkitt-Wright E, Smith R, Toutain A, et al. Xq28 duplication presenting with intestinal and bladder dysfunction and a distinctive facial appearance. Eur J Hum Genet. 2008;17(4):434-43.

24. Parodi S, Vollono C, Baglietto MP, Balestri M, Di Duca M, Landri PA, et al. Congenital centralhypoventilation syndrome: genotype-phenotype correlation in parents of affected children carrying a PHOX2B expansion mutation. Clin Genet. 2010;78(3):289-93.

25. Huang L, Poke G, Gecz J, Gibson K. A novel contiguous gene deletion of AVPR2 and ARHGAP4 genes in male dizygotic twins with nephrogenic diabetes insipidus and intellectual disability. Am J Med Genet. 2012; 158A(10):2511-8.

26. Yu H-C, Sloan JL, Scharer G, Brebner A, Quintana AM, Achilly NP, et al. An X-linked cobalamin disorder caused by mutations in transcriptional coregulator HCFC1. Am J Hum Genet. 2013;93(3):506-14.

27. Shimada S, Okamoto N, Ito M, Arai Y, Momosaki K, Togawa M, et al. MECP2 duplication syndrome in both genders. Brain Dev. 2013:35(5):411-9.

28. Kirk EP, Malaty-Brevaud V, Martini N, Lacoste C, Levy N, Maclean K, et al. The clinical variability of the MECP2 duplication syndrome: description of two families with duplications excluding L1CAM and FLNA. Clin Genet. 2009; 75(3):301-3.

\section{Submit your next manuscript to BioMed Central and we will help you at every step:}

- We accept pre-submission inquiries

- Our selector tool helps you to find the most relevant journal

- We provide round the clock customer support

- Convenient online submission

- Thorough peer review

- Inclusion in PubMed and all major indexing services

- Maximum visibility for your research

Submit your manuscript at www.biomedcentral.com/submit
C Biomed Central 